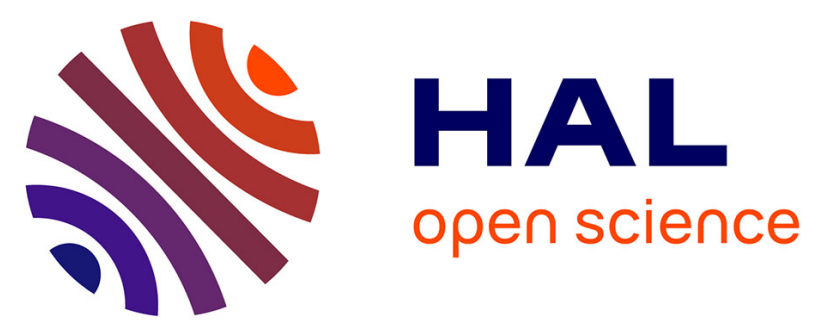

\title{
Molecular analysis of leptospires from serogroup Sejroe obtained from asymptomatic cattle in Rio de Janeiro - Brazil reveals genetic proximity to serovar Guaricura
}

\author{
A.P. Loureiro, C. Hamond, P. Pinto, S. Bremont, Pascale Bourhy, W.
} Lilenbaum

\section{To cite this version:}

A.P. Loureiro, C. Hamond, P. Pinto, S. Bremont, Pascale Bourhy, et al.. Molecular analysis of leptospires from serogroup Sejroe obtained from asymptomatic cattle in Rio de Janeiro - Brazil reveals genetic proximity to serovar Guaricura. Research in Veterinary Science, 2016, 105, pp.249-253. 10.1016/j.rvsc.2016.02.012 . pasteur-02945321

HAL Id: pasteur-02945321

https://hal-pasteur.archives-ouvertes.fr/pasteur-02945321

Submitted on 22 Sep 2020

HAL is a multi-disciplinary open access archive for the deposit and dissemination of scientific research documents, whether they are published or not. The documents may come from teaching and research institutions in France or abroad, or from public or private research centers.
L'archive ouverte pluridisciplinaire HAL, est destinée au dépôt et à la diffusion de documents scientifiques de niveau recherche, publiés ou non, émanant des établissements d'enseignement et de recherche français ou étrangers, des laboratoires publics ou privés.

\section{(ㅇ)(1) $\$$}

Distributed under a Creative Commons Attribution - NonCommercial - NoDerivatives| 4.0 
"Molecular analysis of leptospires from serogroup Sejroe obtained from asymptomatic cattle in Rio de Janeiro - Brazil reveals genetic proximity to serovar Guaricura"

Loureiro, A.P. ${ }^{a}$, Hamond, C. ${ }^{a}$, Pinto, P. ${ }^{a}$, Bremont, S. ${ }^{b}$, Bourhy, P. ${ }^{b}$, Lilenbaum, W. ${ }^{a}$

aLaboratório de Bacteriologia Veterinária, Departamento de Microbiologia e Parasitologia, Universidade Federal Fluminense, Niterói, Rio de Janeiro, Brazil

${ }^{\mathrm{b}}$ Institut Pasteur, Unité de Biologie des Spirochètes, National Reference Center and WHO Collaborating Center for Leptospirosis, Paris, France

*Corresponding authors: W. Lilenbaum, MVD, PhD, Laboratório de Bacteriologia Veterinária, Universidade Federal Fluminense, Rua Hernani Mello 101, 309, Niterói, Rio de Janeiro, 24210-030, Brazil.

Phone: +55 (21) 2629-2435

(E-mail: mipwalt@,vm.uff.br)

Keywords: Cattle; Guaricura; rrs; secY; Serogrouping; Sejroe. 


\begin{abstract}
Bovine leptospirosis causes substantial reproductive failure in cattle, mainly due to infections with serovar (sv) Hardjo infection. Notwithstanding, other serovars from the serogroup (sg) Sejroe could also have important roles in bovine leptospirosis. The objective was to investigate genetic diversity of serogroup Sejroe isolates obtained from asymptomatic cattle in the state of Rio de Janeiro, Brazil. Urine and vaginal fluid (VF) were collected from clinically healthy cattle immediately after slaughter. Five isolates were recovered and characterized (serogrouping) as belonging to sg Sejroe. Sequencing of $r r s$ and $\sec Y$ genes further identified them as Leptospira santarosai. Analysis of secY sequences indicated a high level of sequence homology to sv Guaricura strains. Based on culture and sequence data, we inferred that other members of sg Sejroe may be important in bovine leptospiral infection, particularly genotypes of L. santarosai serovar Guaricura.
\end{abstract}




\section{Introduction}

Leptospirosis causes reproductive failure in livestock worldwide, resulting in substantial financial losses due to infertility and abortion (Ellis, 2015). Leptospira spp., its etiologic agent, has a complex taxonomic classification. Serological classification defines serovars (sv), and serogroups (sg), whereas genotype classification defines genomospecies based on DNA similarity between strains (Cerqueira and Picardeau, 2009).

Serovar identification remains essential for epidemiological studies and for prevention strategies (Ellis, 2015). There is seroepidemiological evidence that serovar Hardjo is prevalent in cattle worldwide (Ellis, 2015; Salgado et al., 2014). Nevertheless, serology can only distinguish from reactions against Hardjo or other members of serogroup Sejroe, because it is merely reliable at a serogroup level (Picardeau, 2013).

There are two known genotypes of sv Hardjo: Hardjoprajitno (L. interrogans) is mainly isolated in Europe, and Hardjobovis (L. borgpetersenii) which prevails in the United States (Rinehart et al., 2012). However, few studies have reported recovery of Hardjo in tropical regions (Aycardi et al., 1980; Feresu et al., 1999; Salgado et al, 2015). Only two L. interrogans Hardjoprajitno strains have been described in Brazil: strains Norma (Cosate et al., 2012) and 2012_OV5 (Director et al., 2014). Additionally, another member of the Sejroe serogroup (L. santarosai sv. Guaricura) was obtained from cattle and buffalo (Santa Rosa et al., 1980; Vasconcellos et al., 2001).

There are indications that Hardjo may not be the only member of sg Sejroe infecting cattle under tropical conditions. Indeed, without bacteriological and molecular confirmation, it is not possible to understand the true frequency and the role of each serovar from the same serogroup. Therefore, the objective was to investigate genetic 
diversity of serogroup Sejroe isolates obtained from asymptomatic cattle in the state of Rio de Janeiro, Brazil.

\section{Material and Methods}

From December 2013 to December 2014, a total of 200 cattle (189 females and 11 males) were randomly selected in an abbatoir located close $(130 \mathrm{~km})$ to Rio de Janeiro, Brazil. All of these cattle were adults and originated from nearby herds. Cattle origin and individual history were not provided; notwithstanding, there was no particular reference to reproductive or sanitary problems in those herds. All cattle were considered healthy on ante mortem clinical examination and none had any apparent clinical signs of disease. Samples of urine $(\mathrm{N}=200)$ and vaginal fluid $(\mathrm{VF}, \mathrm{N}=189)$ were collected. Urine samples were collected by direct puncture of the bladder, whereas VF was obtained from the vaginal fornix using cytology brushes (Kolplast, Itupeva, SP, Brazil).

Immediately after collection, a few drops of urine were seeded into tubes with EMJH medium (DIFCO, BD, Franklin Lakes, NJ, USA), Fletcher medium (DIFCO, BD, Franklin Lakes, NJ, USA) and EMJH medium supplemented with an antimicrobial cocktail named STAFF (Chakraborty et al., 2011). Each vaginal brush was dipped into one tube of each medium. Tubes were maintained at room temperature and transported to the laboratory. Cultures were incubated at $28{ }^{\circ} \mathrm{C}$ and evaluated weekly (dark-field microscopy) for up to $16 \mathrm{wk}$. Filtration $(0.22 \mu \mathrm{m}$ sterile syringe filter; Millipore Corporation, Billerica, MA, USA) or a subculture to a new EMJH-STAFF tube was made if there was apparent contamination by other microorganisms.

Isolates were tested by Microscopic agglutination test (MAT) against a panel of rabbit antisera of 32 reference serovars, representing 24 serogroups (provided by Royal Tropical Institute - KIT, Amsterdam), as recommended (Haake and Levett, 2015). 
Additionally, isolates with reactivity against the serogroup Sejroe were tested with rabbit antisera against serovar Guaricura (provided by Dr. Silvio Vasconcellos, São Paulo USP, Brazil). Therefore, antisera from sg Sejroe comprised serovars Wolffi, Hardjoprajitno, Hardjobovis (KIT) and Guaricura (USP).

Molecular characterization was conducted at the Unit of Biology of Spirochetes, Institut Pasteur, Paris, France. First, DNA was extracted from isolates using the Promega Wizard SV Genomic DNA Purification System ${ }^{\circledR}$ (Promega, Madison, WI, USA). Primers $\mathrm{F} \quad\left(5^{\prime}\right.$-ATGCCGATCATTTTTGCTTC-3') and R (5'CCGTCCCTTAATTTTAGACTTCTTC -3') were used for amplification of the partial gene $\sec Y$ (Ahmed et al., 2006). The primers LA (5'-GGCGGCGCGTCTTAAACATG3') and LB (5'-TTCCCCCCATTGAGCAAGATT-3'; Mérien et al., 1992) were used to partially amplify the $r r s$ gene. Amplicons of partial $\sec Y$ gene and partial $r r s$ gene were sequenced at the Genotyping of Pathogens and Public Health Platform (Institut Pasteur, Paris, France) according to Bourhy et al. (2013). Molecular epidemiological data were stored and analyzed with Bionumerics software (Version 6.5; Applied-Maths, SintMartens-Latem, Belgium). A phylogenetic tree was drawn using Nearest Neighbor Interchanges (NNIs), and reliability of branches was evaluated by generation of 1000 "bootstrap" replicates (Guindon et al., 2010). Deduced amino acid sequences were obtained on ORF Finder tool (http://www.ncbi.nlm.nih.gov/gorf/orfig.cgi) and alignments were performed on Clustal IX 2.1.

\section{Results}

From the 389 cultures, we obtained $11(2.8 \%)$ isolates, seven from urine $(63.6 \%)$ and four from VF (36.4\%), all from different animals. From these, five isolates (45.5\%) 
belonged to the serogroup Sejroe (Table 1). Isolates of other serogroups (Australis, Autumnalis and Tarassovi) will be characterized in detail elsewhere. All of the five isolates were first observed on EMJH supplemented with STAFF after 2 or 3 wk of incubation. Three were obtained from urine, designated 2014_U76 (KP645175), 2014_U81 (KP645176) and 2014_U140 (KP645177), and two from VF, named 2013_VF52 (KP645174) and 2014_VF66 (KP645178). Those five isolates were genetically analyzed by sequencing $r r s$ and $\sec Y$ partial genes.

Genetic characterization of all five $r r s$ gene fragments clustered isolates into a pathogenic group belonging to the L. santarosai genomospecies (Fig. 1). Sequencing of $\sec Y$ partial gene was conducted for a broader analysis of those five strains in relation to other Sejroe members recovered in Brazil and other regions (available on GenBank). Both isolates from VF (2013_VF52 and 2014_VF66) were identical to each other; similarly, 2014_U140 was identical to the previously described 2013_U214 (Hamond et al., 2015), which was also isolated from bovine urine in the same region (Fig 2). Moreover, alignment of $549 \mathrm{bp} \sec Y$ DNA sequences to other strains of sg Sejroe, had few polymorphisms $(<5 \%)$ among isolates, which are all similar to M04-98 and BovG Guaricura strains (Fig. 3). Based on alignment of translated sequences from the eight strains (five isolates, 2013_U214 and two Guaricura strains), there were no amino acid changes, except for one $(\mathrm{I} \rightarrow \mathrm{V})$ on 2013_VF52 and 2014_VF66 strains when compared to the other six strains (Fig 4).

A dendogram of partial $\sec Y$ analysis (Fig. 2) established three phylogenetic clades that facilitated distinguishing strains into genomospecies (L. borgpetersenii, $L$. interrogans and L. santarosai). Two clusters were observed within the L. santarosai clade. Although strains recovered from VF (2013_VF52 and 2014_VF66) were slightly 
distinct, all strains from urine samples clustered closely to Guaricura strains (BovG and M04-98).

\section{Discussion}

The most important outcome of the present study was that we cultured five isolates serologically classified as serogroup Sejroe, all Leptospira santarosai from randomly sampled asymptomatic cattle. Although four of the five new strains had higher titres for anti-Hardjoprajtino antiserum, MAT results were only reliable on a serogroup level. Specifically, only the cross absorption agglutination test (CAAT) is a recommended method to determine sorovar as a basic taxon (Galloway and Levett, 2010). Moreover, anti-Guaricura antiserum was not provided by the same source (KIT), and possible variations regarding antiserum potency cannot be excluded.

Serological and molecular classifications are not related; therefore, members of the same serogroup frequently belong to different species (Cerqueira and Picardeau, 2009). Strains of sg Sejroe have been reported among various genomospecies, including L. interrogans, L. borgpetersenii (Rinehart et al., 2012) and L. santarosai (Vasconcellos et al., 2001). Particularly in the tropics, members of that serogroup were reported as $L$. santarosai and L. interrogans in Brazil (Director et al., 2014; Santa Rosa et al., 1980; Vasconcellos et al., 2001); L. santarosai in the Carribean (Green et al., 1978; Sulzer et al., 1982), L. borgpetersenii in Zimbabwe (Feresu et al., 1999), L. interrogans in Malaysia (Bahaman et al., 1990), and as L. weilii in Indonesia (Bahaman et al., 1990), what reinforced the high genetic diversity among members of the same serogroup.

Interestingly, partial $\sec Y$ sequencing demonstrated that all obtained isolates had close homology to L. santarosai serovar Guaricura. In the same cluster, there were other 
L. santarosai strains, including Recreo, Caribe and Gorgas, which were obtained from various rodent species in the Caribbean region; therefore, perhaps these genotypes are widely disseminated in Latin America. Interestingly, two isolates recovered from VF were grouped in a different cluster in L. santarosai clade. In silico comparison of translated sequences revealed only one polymorphic site resulted in an amino acid change. Since that mutation led to replacement of one nonpolar amino acid with another nonpolar, it probably did not constitute an alteration of protein structure or function (Koehl and Delarue, 1994).

The low number of isolates hampered a broader epidemiological understanding of the role of those strains with regards to bovine leptospirosis. Regardless, it was remarkable that they represented genotypes of $L$. santarosai serovar Guaricura. Perhaps they are disseminated in bovines in the studied region. This was quite unexpected, since strains of L. interrogans serovar Hardjo are generally considered the major agents of bovine leptospirosis in the region. Consequently, our findings may affect diagnosis, prevention and control of bovine leptospirosis in the region. Diagnostic protocols (including serology) and vaccines are mostly based on L. interrogans sv. Hardjoprajtino reference strains (Rinehart et al., 2012), and its reliability for detecting and preventing infections caused by other members of sg Sejroe remains to be confirmed. Indeed, in a recent study, inclusion of the reference strain Guaricura (M04-98) as antigen for MAT increased its sensitivity by $6 \%$ in Brazilian herds (Sarmento et al., 2012). However, to our knowledge, those strains have never been tested for vaccine purposes.

\section{Conclusion}


In conclusion, although it is clear that the main agents of bovine leptospirosis worldwide belong to serogroup Sejroe, that serogroup is distributed among various leptospiral species and genotypes. Thus, it is possible to suggest that not only sv Hardjo, but also other members of sg Sejroe, particularly genotypes of L. santarosai serovar Guaricura, may be disseminated in cattle in the studied region. Those findings should be considered in ongoing efforts to improve the diagnosis, prevention and control of bovine leptospirosis.

\section{Conflict of interest statement}

Nothing to declare.

\section{Acknowledgements}

The authors thank the abbatoir owner (Frigorifico Esteves), who allowed collection of samples. We are also thankful to MSc. L. Narduche, H. Libonati (UFF) for their help in collecting samples, to Dr. Silvio Vasconcellos (USP) for providing the anti-Guaricura antiserum, Leonardo Almeida, Fabio Navarro (Yale University) for their help in English writing and Jonh Kastelic (University of Calgary) for the critical English revision. This study was supported by FAPERJ - Fundação de Amparo à Pesquisa do Estado do Rio de Janeiro. PP is a CAPES fellow. CH, WL are CNPq fellows. APL and WL are FAPERJ fellows.

\section{References}

Ahmed, N., Devi, S. M., Valverde, Mde. L., Vijayachari, P., Machang'u, R.S., Ellis, W.A., Hartskeerl, R.A, 2006. Multilocus sequence typing method for identification and genotypic classification of pathogenic Leptospira species. Annals of Clinical Microbiology and Antimicrobials 5, 28. 
Aycardi, E. R., Torres, B., Guzmán, V. H., Cortés, M., 1980. Leptospirosis in Colombia. Isolation of Leptospira hardjo from beef cattle grazing tropical savannas. Revista latinoamericana de microbiología 22, 73-77.

Bahaman, A. R., Ibrahim, A.L., Stallman, N.D., 1990. Leptospira interrogans serovar Unipertama isolated in Malaysia. International journal of systematic and evolutionary microbiology 40, 98-99.

Bourhy, P., Herrmann Storck, C., Theodose, R., Olive, C., Nicolas, M., Hochedez, P., Lamaury, I., Zinini, F., Brémont, S., Landier, A., Cassadou, S., Rosine, J., Picardeau, M., 2013. Serovar diversity of pathogenic Leptospira circulating in the French West Indies. PLOS Neglected Tropical Diseases 7, e2114.

Cerqueira, G. M., Picardeau, M., 2009. A century of Leptospira strain typing. Infection, Genetics and Evolution 9, 760-768.

Chakraborty, A., Miyahara, S., Villanueva, S. Y., Saito, M., Gloriani, N. G., Yoshida, S., 2011. A novel combination of selective agents for isolation of Leptospira species. Microbiology Immunology 55, 494-501.

Cosate, M.R., Barouni, A. S., Moreira, E.C., Veloso, I. F., Gomes, M. T., Salas, C. E., 2012. Molecular characterization by LSSP-PCR and DNA sequencing of a pathogenic isolate of Leptospira interrogans from Brazil. Zoonoses and Public Health 59, 379-388.

Director, A., Penna, B., Hamond, C., Loureiro, A. P., Martins, G., Medeiros, M. A., Lilenbaum, W., 2014. Isolation of Leptospira interrogans Hardjoprajitno from vaginal fluid of a clinically healthy ewe suggests potential for venereal transmission. Journal of Medical Microbiology 63, 1234-1236. 
Ellis, W. A., 2015. Animal leptospirosis. Current Topics in Microbiology Immunology 387, 99-137.

Feresu, S. B., Steigerwalt, A. G., Brenner, D. J., 1999. DNA relatedness of Leptospira strains isolated from beef cattle in Zimbabwe. International journal of systematic bacteriology 49, 1111-1117.

Galloway, R. L., Levett, P. N., 2010. Application and validation of PFGE for sorovar identification of Leptospira clinical isolates. PLoS Neglected Tropical Diseases 4, e824.

Green, A. E., Sulzer, C. R., Evarard, C. O., Jones, W.L., 1978. Four new Leptospira serotypes from Trinidad. West Indian Medical Journal 27, 117-126.

Guindon, S., Dufayard, J.F., Lefort, V., Anisimova, M., Hordijk, W., Gascuel, O., 2010. New algorithms and methods to estimate Maximum-Likelihood Phylogenies: Assessing the performance of PhyML 3.0. Systematic Biology 59, 307-321.

Haake, D.A., Levett, P.N., 2015. Leptospirosis in humans. Current Topics Microbiology Immunology, 387, 65-97.

Hamond, C., Pinna, M. H., Martins, G., Medeiros, M. A., Lilenbaum, W., 2015. Infection by Leptospira spp. in cattle in a tropical region, Rio de Janeiro, Brazil. The American Journal of Tropical Medicine and Hygiene 92, 210.

Koehl, P., Delarue, M., 1994. Polar and nonpolar atomic environments in the protein core: implications for folding and binding. Proteins, 20, 264-78.

Mérien, F., Amouriaux, P., Perolat, P., Baranton, G., Saint Girons, I., 1992. Polymerase chain reaction for detection of Leptospira spp. in clinical samples. Journal of Clinical Microbiology 30, 2219-2224. 
Picardeau, M., 2013. Diagnosis and epidemiology of leptospirosis. Médecine et Maladies Infectieuses 43, 1-9.

Rinehart, C.L., Zimmermanm, A. D., Buterbaugh, R. E., Jolie, R. A., Chase, C. C., 2012. Efficacy of vaccination of cattle with the Leptospira interrogans serovar Hardjo type Hardjoprajitno component of a pentavalent Leptospira bacterin against experimental challenge with Leptospira borgpetersenii serovar Hardjo type Hardjo-bovis. American Journal of Veterinary Research 73, 735-740.

Salgado, M., Otto, B., Sandoval, E., Reinhardt, G., Boqvist, S., 2014. A cross sectional observational study to estimate herd level risk factors for Leptospira spp. serovars in small holder dairy cattle farms in southern Chile. BMC Veterinary Research 10, 126.

Salgado, M., Otto, B., Moroni, M., Sandoval, E., Reinhardt, G., Boqvist, S., Encina, C., Muñoz-Zanzi, C., 2015. Isolation of Leptospira interrogans serovar Hardjoprajitno from a calf with clinical leptospirosis in Chile. BMC Veterinary Research, 11, 66.

Santa Rosa, C. A., Sulzer, C. R., de Castro, A. F., Yanaguita, R. M., Giorgi, W., 1980. Two new leptospiral serovars in the Hebdomadis group isolated from cattle in Brazil. The International Journal of Zoonoses 7, 158-163.

Sarmento, A. M. C, Azevedo, S. S., Morais, Z. M., Souza, G. O., Oliveira, F. C. S., Gonçales, A. P., Miraglia, F., Vasconcellos, S. A., 2012. Emprego de estirpes Leptospira spp. isoladas no Brasil na microtécnica de soroaglutinação microscópica aplicada ao diagnóstico da leptospirose em rebanhos bovinos de oito estados brasileiros (Use of Leptospira spp. strains isolated in Brazil in the microscopic agglutination test applied to diagnosis of leptospirosis in cattle herds in eight brazilian states). Pesquisa Veterinária Brasileira 32, 601-606. 
Sulzer, K., Pope, V., Rogers, F., 1982. New leptospiral serotypes (serovars) from the Western Hemisphere isolated during 1964 through 1970. Revista latinoamericana de microbiología 24, 15-17.

Vasconcellos, S. A., Oliveira, C. F. J., Morais, Z. M., Baruselli, P. S., Amaral, R., Pinheiro, S.R., Ferreira, F., Ferreira- Neto, J. S., Schönberg, A., Hartskeerl, R. A., 2001. Isolation of Leptospira santarosai, serovar Guaricura from buffaloes (Bubalus bubalis) in Vale do Ribeira, São Paulo, Brazil. Brazilian Journal of Microbiology 32, 298-300. 
Table 1. Serogrouping of five leptospiral isolates obtained from urine (U) and vaginal fluid (VF) of cattle in the state of Rio de Janeiro, Brazil.

\begin{tabular}{lcccc}
\hline Isolate & Anti-Wolffi & Anti-Hardjoprajitno & Anti-Hardjobovis & Anti-Guaricura \\
\hline 2014_U76 & 6,400 & 12,800 & 3,200 & 6,400 \\
2014_U81 & 6,400 & 12,800 & 1,600 & 6,400 \\
2014_VF52 & 6,400 & 12,800 & 3,200 & 6,400 \\
2014_VF66 & 6,400 & 12,800 & 1,600 & 6,400 \\
2014_U140 & 800 & 3,200 & 1,600 & 3,200 \\
\hline
\end{tabular}




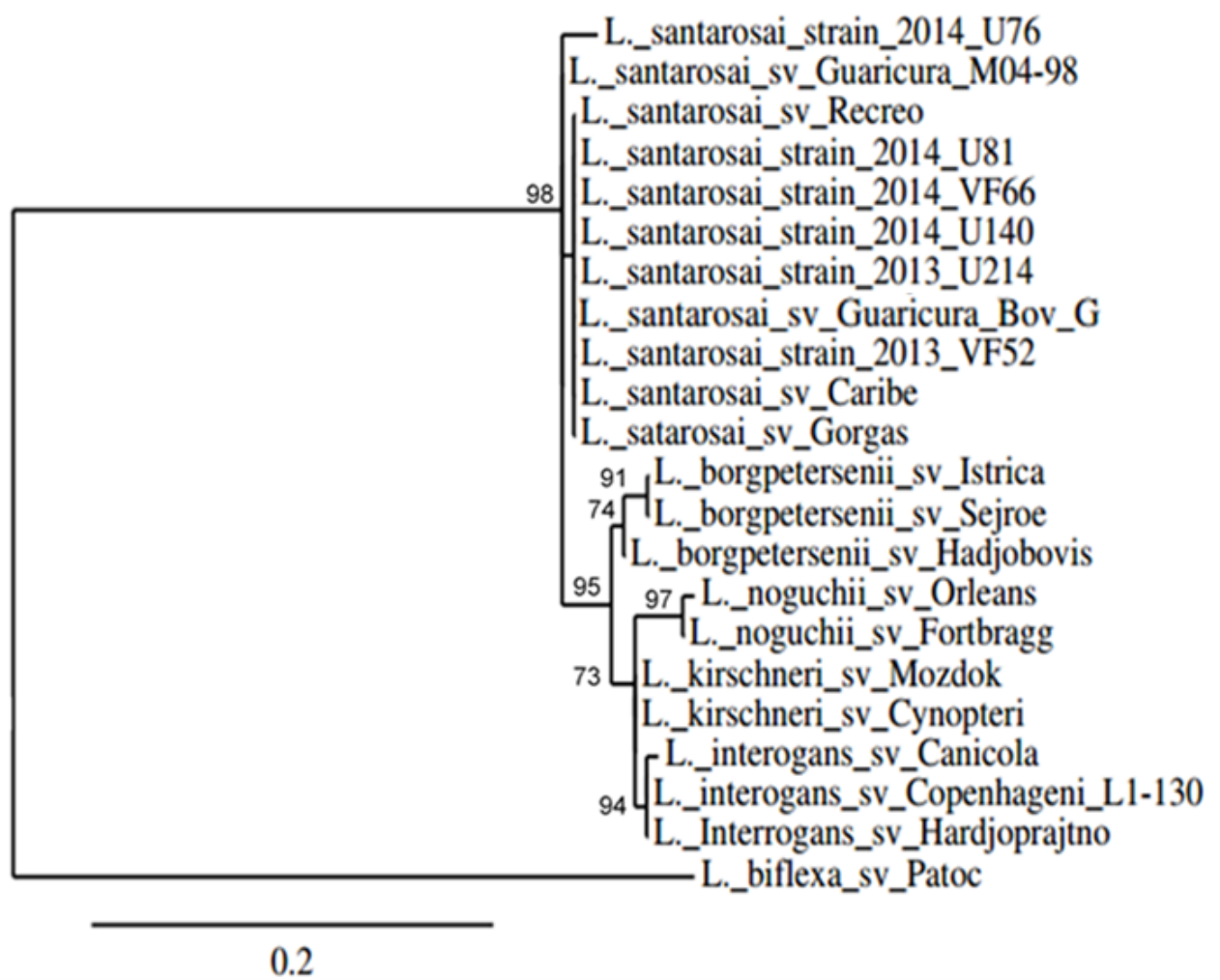

Fig.1. Phylogenetic tree of leptospiral partial $r r s$ gene sequences of reference strains and a set of clinical isolates from cattle (2013_U214, 2014_U76, 2014_U81, 2013_VF52, 2014_VF66 and 2014_U140). The phylogenetic tree was drawn using the Nearest Neighbor Interchanges (NNIs). Reliability of the branches was validated by the generation of 1000 "bootstrap" replicates. Reference strains: L. santarosai sv. Recreo strain 380 (Opossum, Nicaragua), sv. Caribe strain TRVL61866 (Rat, Trinidad), sv. Guaricura strain BovG (Bovine, Brazil) and M04-98 (Water Buffalo, Brazil), sv. Gorgas strain 1413U (Spiny Rat, Panama), 2013_U214 (Bovine, Brazil); L. borgpetersenii sv Istrica strain Bratislava (Wood Mouse, Czech Republic), sv. Sejroe strain M84 (mouse, Denmark), sv. Hardjobovis strain JB197; L.interrogans sv. Canicola strain LT1962 (Human, Taiwan); sv Copenhageni strain Fiocruz L1-130, sv. Hardjoprajitino (Human, Indonesia); and L. biflexa sv Patoc strain Patoc1. 


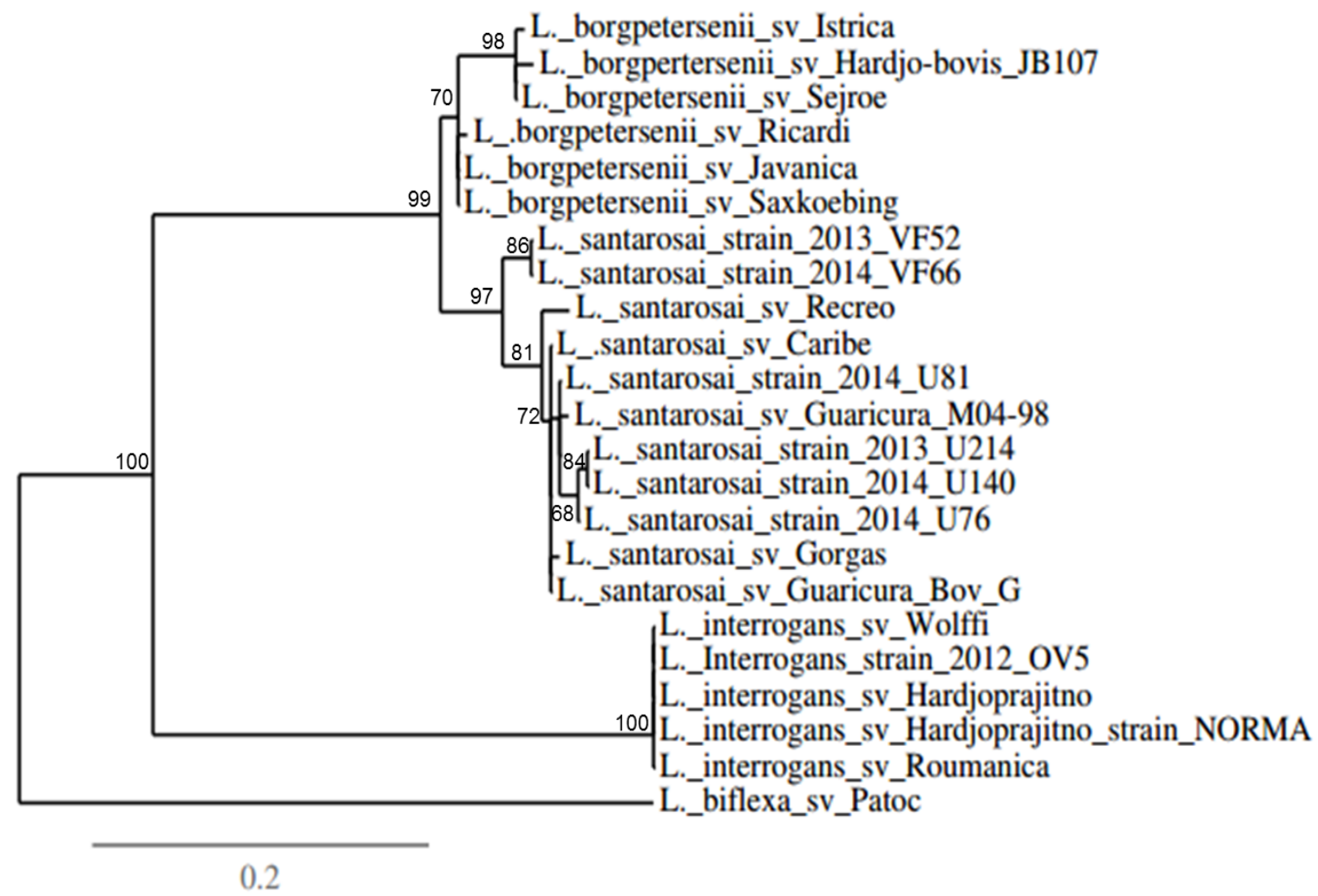

Fig.2. Phylogenetic tree of leptospiral partial $\sec Y$ gene sequences of reference strains and a set of clinical isolates from cattle (2013_U214, 2014_U76, 2014_U81, 2013_VF52, 2014_VF66 and 2014_U140). The phylogenetic tree was drawn using the Nearest Neighbor Interchanges (NNIs). Reliability of the branches was validated by the generation of 1000 "bootstrap" replicates. Reference strains: L. santarosai sv. Recreo strain 380 (Opossum, Nicaragua), sv. Caribe strain TRVL61866 (Rat, Trinidad), sv. Guaricura strain BovG (Bovine, Brazil) and M04-98 (Water Buffalo, Brazil), sv. Gorgas strain 1413U (Spiny Rat, Panama), 2013_U214 (Bovine, Brazil); L. borgpetersenii sv Istrica strain Bratislava (Wood Mouse, Czech Republic), sv. Sejroe strain M84 (mouse, Denmark), sv. Hardjobovis strain JB197, sv. Ricardi strain Richardson (Human, Malasya), sv. Saxkoebing strain Mus24 (Wood mouse, Denmark), sv. Javanica strain Veldrat Batavia 46 (Field rat, Indonesia); L.interrogans sv. Hardjo strain Hardjoprajitino (Human, Indonesia), strain 2012_OV5 (ovine, Brazil), strain NORMA (bovine, Brazil), Roumanica strain TM294 (Mus musculus, Romania), Wolffi strain 3705 (Human, Indonesia); and L. biflexa sv Patoc strain Patoc1. 


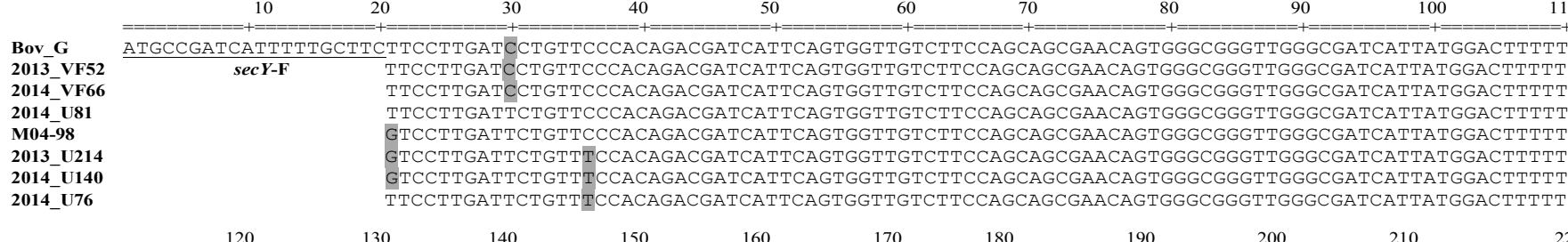

120

130

160

170

180

220

Bov_G CAATCCGTTCTCCCAGATCTGGTATCACGCATTGTTCTACTTTGTGATCTATACTTCTTTGATTATHTTCTTCGCA ACTTTTTACA

2013_VF52 CAATCCATTCTCCCAAATCTGGTATCACGCATTGTTTTACTTCGTGATCTATACTTCATTGATCGTGTTCTTCGCATACTTTTACACTGCGATTCAGTTCAACCCTGCGC

2014_U81 CAATCCGTTCTCCCAGATCTGGTATCACGCATTGTTCTACTTTGTGATCTATACTTCTTTGATTATTTTCTTCGCATACTTTTACACTGCGATTCAGTTCAACCCTGCGG

M04-98 CAATCCGTTCTCCCAGATCTGGTATCACGCATTGTTCTACTTTGTGATCTATACTTCTTTGATTATTTTCTTCGCATACTTTTACACTGCGATTCAGTTCAACCCTGCG

2013_U214 C

2014-U76

CAATCGTTCTCGCAGATCTGGTATCACGCATTGTTCTACTTGTGATCTATACTTCTTTGATTATTTTCTTCGCATACTTTTACACTGCGATTCAGTTCAACCCTGCG
CAATCCGTTCTCGCAGATCTGGTATCACGCATTGTTCAATTTGTGATCTATACTTCTTTGATTATTTTCTTCGCATACTTTTACACTGCGATTCAGTTCAACCCTGCGG

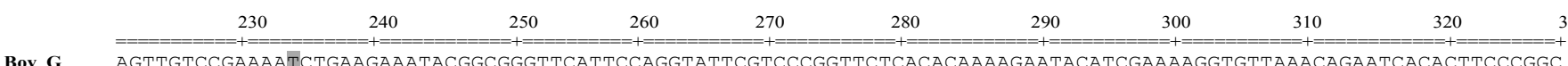

2013_VF52 AGTTGTCCGAAAACCTGAAGAAATACGGCGGGTTCATTCCAGGTATTCGTCCCGGTTCTCACACAAAAGAATACATCGAAAAGGTGTTAAACAGAATCACACTTCCCGGC

2014_VF66 AGTTGTCCGAAAACCTGAAGAAATACGGCGGGTTCATTCCAGGTATTCGTCCCGGTTCTCACACAAAAGAATACATCGAAAAGGTGTTAAACAGAATCACACTTCCCGGC

2014_U81 AGTTGTCCGAAAACCTGAAGAAATACGGCGGGTTCATTCCAGGTATTCGTCCGGTTCTCACACAAAAGAATACATCGAAAAGGTGTTAAACAGAATCACACTTCCCGGC
$\mathbf{1 0 4 - 9 8}$

2013 - 1214

2014_U140

2014_U76

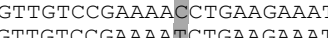

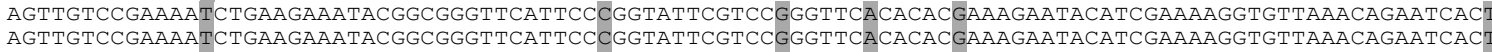

GAAGAAATACGGCGGGTTCATTC

CCGGGTTCACACACGAAAGAATACATCGAAAAGGTGTTAAACAGAATCAC

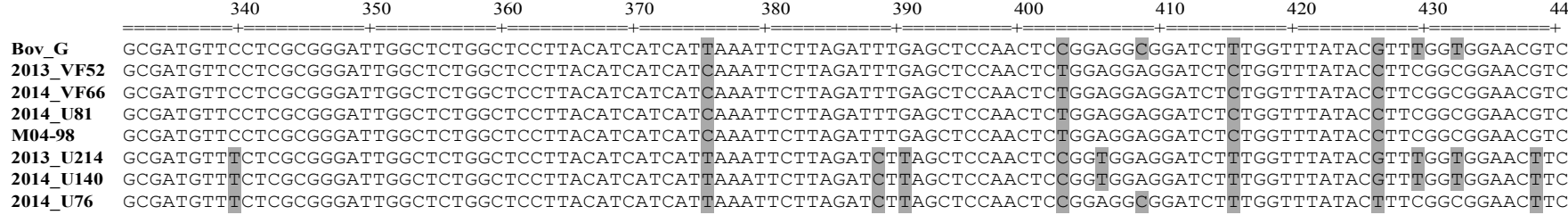

460

470

480

490

500

510

520

530

540

Bov_G CCTCTTGATTATGGTAGGGTTGCGCTCGAGACTTTAAAACAAATCGAGTCTCACTTTTGATGAGAAACTACGAAGGCTTCATGAAGAAGTCTAAAATTAAGGGACGG

2014-VF66 CCTCTTGATTATGGTAGGGGTTGCGCTCGAGACTTTGAAACAAATCGAGTCTCAACTTTTGATGAGAAACTACGAAGGCTTCATGAA

2014 U81 CCTCTGATATGGTAGGGGTGCGCTGAGACITTGAAACAAATCGAGICTCAACTTTTGATGAGAAACTACGAAGGCTTCATGAA

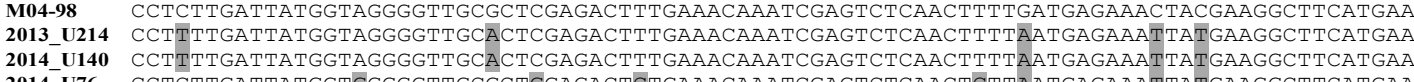

2014_U76 CCTCTTGATTATGGTGGGGGTTGCGCTGGAGACTCTGAAACAAATCGAGTCTCAACTCTTAATGAGAAATTATTAAGGC

Fig 3. Alignment of partial secY (549 bp) amplified with primers $\sec Y-\mathrm{F} / \sec Y$ - from a set of clinical isolates from cattle (2013_U214, 2014_U76,

2014_U81, 2013_VF52, 2014_VF66 and 2014_U140) and sv Guaricura reference strains (M04-98 and BovG). Polymorphisms are highlighted in grey. 
MPIIFASSLILFPQTIIQWLSSSSEQWAGWAIIMDFFNPFSQIWYHALFYFVIYTSLI I FFAYFYTAIQFNPAELSENLKKYGGFIPGIRPGSHTKEYIEKVLNRITLPGAM MPIIFASSLILFPQTILQWLSSSSEQWAGWAIIMDFFNPFSQIWYHALFYFVIYTSLI I FFAYFYTAIQFNPAELSENLKKYGGFIPGIRPGSHTKEYIEKVLNRITLPGAM MPIIFASSLILFPQTIIQWLSSSSEQWAGWAIIMDFFNPFSOIWYHALFYFVIYTSLI I FFAYFYTAIOFNPAELSENLKKYGGFIPGIRPGSHTKEYIEKVLNRITLPGAM MPIIFASSLILFPQTIIQWLSSSSEQWAGWAIIMDFFNPFSQIWYHALFYFVIYTSLI I FFAYFYTAIQFNPAELSENLKKYGGFIPGIRPGSHTKEYIEKVLNRITLPGAM MPIIFASSLILFPQTIIQWLSSSSEQWAGWAIIMDFFNPFSQIWYHALFYFVIYTSLI I FFAYFYTAIQFNPAELSENLKKYGGFIPGIRPGSHTKEYIEKVLNRITLPGAM MPIIFASSLILFPQTIIQWLSSSSEQWAGWAIIMDFFNPFSQIWYHALFYFVIYTSLI I FFAYFYTAIQFNPAELSENLKKYGGFIPGIRPGSHTKEYIEKVLNRITLPGAM MPIIFASSLILFPQTIIQWLSSSSEQWAGWAIIMDFFNPFSQIWYHALFYFVIYTSLIVFFAYFYTAIQFNPAELSENLKKYGGFIPGIRPGSHTKEYIEKVLNRITLPGAM MPIIFASSLILFPQTIIQWLSSSSEQWAGWAIIMDFFNPFSQIWYHALFYFVIYTSLIVFFAYFYTAIQFNPAELSENLKKYGGFIPGIRPGSHTKEYIEKVLNRITLPGAM

FLAGLALAPYIIIKFLDLSSNSGGGSLVYTFGGTSLLIMVGVALETLKQIESQLLMRNYEGFMKKSKIKGR FLAGLALAPYIIIKFLDLSSNSGGGSLVYTFGGTSLLIMVGVALETLKQIESQLLMRNYEGFMKKSKIKGR FLAGLALAPYIIIKFLDLSSNSGGGSLVYTFGGTSLLIMVGVALETLKQIESQLLMRNYEGFMKKSKIKGR FLAGLALAPYIIIKFLDLSSNSGGGSLVYTFGGTSLLIMVGVALETLKQIESQLLMRNYEGFMKKSKIKGR FLAGLALAPYIIIKFLDLSSNSGGGSLVYTFGGTSLLIMVGVALETLKQIESQLLMRNYEGFMKKSKIKGR FLAGLALAPYIIIKFLDLSSNSGGGSLVYTFGGTSLLIMVGVALETLKQIESQLLMRNYEGFMKKSKIKGR FLAGLALAPYIIIKFLDLSSNSGGGSLVYTFGGTSLLIMVGVALETLKQIESQLLMRNYEGFMKKSKIKGR FLAGLALAPYIIIKFLDLSSNSGGGSLVYTFGGTSLLIMVGVALETLKQIESQLLMRNYEGFMKKSKIKGR

Fig. 4 Alignment of in silico-translated sequences from a set of clinical isolates from cattle (2013_U214, 2014_U76, 2014_U81, 2013_VF52, 2014_VF66 and 2014_U140) and sv Guaricura reference strains (M04-98 and BovG). Amino acid changes are highlighted in grey. 
